\title{
Sequencing, Speech Production, and Selective Effects of Aging on Phonological and Morphological Speech Errors
}

\author{
Donald G. MacKay \\ University of California, Los Angeles
}

\author{
Lori E. James \\ University of Colorado at Colorado Springs
}

\begin{abstract}
To test age-linked predictions of node structure theory (NST) and other theories, young and older adults performed a task that elicited large numbers of phonological and morphological speech errors. Stimuli were visually presented words containing either $/ \mathrm{p} /$ or $/ \mathrm{b} /$, and participants changed the $/ \mathrm{p} /$ to $/ \mathrm{b} /$ or vice versa and produced the resulting word as quickly as possible. For example, the correct response was "bunk" for the stimulus PUNK, and "ripped" for RIBBED. Consistent with NST predictions, the elicited speech errors exhibited selective effects of aging. Some error types decreased with aging. For example, young adults produced more nonsequential substitution errors (as a percentage of total errors) than older adults (e.g., intended bills misproduced as "gills"). However, other error types remained constant or increased with aging. For example, older adults produced more omission errors than young adults, especially omissions involving inflectional endings (e.g., intended ripped misproduced as "rip"). In addition, older adults exhibited special difficulties with 2 types of phonological and morphological

sequencing processes.
\end{abstract}

Selective age-linked effects are a common pattern in cognitive aging research (see e.g., Burke, MacKay, \& James, 2000). With appropriate controls for sensory deficits, encoding of new information, and working memory overload, language comprehension exhibits much smaller age-linked deficits than does language production.

Major age-linked declines occur in a wide variety of production tasks, such as everyday word retrieval and production of a target word from its definition (e.g., Burke, MacKay, Worthley, \& Wade, 1991) or from its initial letter and semantic category (e.g., McCrae, Arenberg, \& Costa, 1987); reading and producing isolated words under time pressure (e.g., Schmitter-Edgecombe, Vesneski, \& Jones, 2000); naming pictures, objects, and actions (e.g., Au et al., 1995); producing pronouns in sentences (e.g., Kemper, 1992); and

Editor's Note. Elizabeth A. Maylor served as the action editor for this article.-LLL

Donald G. MacKay, Psychology Department, University of California, Los Angeles; Lori E. James, Department of Psychology, University of Colorado at Colorado Springs.

Portions of this research were presented at the April 2000 Cognitive Aging Conference, Atlanta, Georgia, and at the 2001 Annual Meeting of the Psychonomic Society, Orlando, Florida. This research was supported by National Institute on Aging Grant R01 AG 09755 to Donald G. MacKay.

We thank Deborah Burke, Trevor Harley, Michael Vitevich, and Jennifer Taylor for helpful comments on a draft of the article, Paula Adkins, Amy Flynt, Max Gallardo, Diane Marian, and Meghan Gould for research assistance, and Irwin Stein for recruiting participants.

Correspondence concerning this article should be addressed to Donald G. MacKay, Psychology Department, University of California, Los Angeles, CA 90095-1563. E-mail: mackay@psych.ucla.edu producing the spelling of familiar, irregularly spelled words (e.g., MacKay, Abrams, \& Pedroza, 1999).

However, aging seems to impair lower (phonological) levels of language production more than higher (semantic) levels (see Burke et al., 2000, for a review), and the goal of the present study was to develop a detailed understanding of how aging affects production of phonological and morphological units. Our first question was whether aging impairs all aspects of production at these levels or whether here too aging selectively impairs some aspects but not others. To address this question, we examined how aging affects different types of speech errors or "slips of the tongue."

Speech errors occur when a speaker intends to produce a familiar word but inadvertently misproduces one or more speech sounds in the word, as when one intends to say box of flowers but instead says "blocks of flowers," anticipating the /1/ in flowers. ${ }^{1}$ Such errors provide a window into the mechanisms underlying everyday language production and have received a great deal of attention in the cognitive sciences over the past 100 years. Descriptive studies involving large collections of naturally occurring errors in young and middle-aged adults (e.g., Fromkin, 1973; Meringer \& Mayer, 1895) and children (e.g., MacKay, 1970) have cross-classified errors on the basis of two factors: the type of process and the level of the units produced in error. The present study focused on single segments and suffixes as the units of interest and on omission, substitution, and addition as the processes of interest. To contrast single-segment units with suffix units in naturally occurring errors, compare the errors "bake fluid" instead of (intended) brake fluid

\footnotetext{
${ }^{1}$ To distinguish spoken (phonological) units from written (orthographic) units, we follow the usual convention of indicating phonological units in International Phonetic Alphabet transcription within slashes (e.g., /p/) and orthographic units within square brackets (e.g., [P]). The stimulus words are indicated in capital letters.
} 
versus "New Yorkan" instead of (intended) New Yorker (from Fromkin, 1973): The first is a phonological error involving omission of a single segment, $/ \mathrm{r} /$, whereas the second is a morphological error involving substitution of one suffix (-an, seen, e.g., in American) for another (-er). To contrast addition versus omission processes in naturally occurring errors, "golden" instead of (intended) gold involves addition of the suffix /-en/, whereas "bake fluid" instead of brake fluid involves omission of the segment /r/.

Because speech errors are relatively rare and difficult to observe in everyday speech, techniques have been developed to elicit errors in large numbers in the laboratory, thereby allowing sophisticated statistical analyses and greater reliability in specifying the intended output and the processes underlying different types of errors (see e.g., Baars, Motley, \& MacKay, 1975; MacKay, 1971, 1976). Many interesting studies have adopted these error-induction techniques, but no previous published study has involved older adults. However, Mahoney (1997) used the Baars et al. (1975) technique to elicit phonological anticipations, perseverations, and transpositions (e.g., unintended production of "darn bore" instead of barn door) in young and older adults. Mahoney's goal was to test for selective age effects predicted in Dell, Burger, and Svec (1997): an age-linked increase in perseverations (labeled "bad" errors because they reflect a focus on the past) and an age-linked decrease in anticipations (labeled "good" errors because they reflect a focus on the future). However, even though older adults made more errors overall than young adults, Mahoney failed to detect selective age effects because anticipations and perseverations were so rare $(1 \%$ or less of all trials). It was for this reason that the present study adopted the error-induction paradigm known as the transform technique (MacKay, 1976, 1978), which induces the errors of current interest in large numbers: omissions, additions, and substitutions of phonological segments and suffixes.

\section{Theoretical Issues}

\section{Speech Errors, Aging, and the Problem of Serial Order in Behavior}

Lashley (1951) first emphasized the importance of speech errors for theories of serial order, and sequencing processes currently represent a highly active theoretical topic (see, e.g., Burgess, 1995) with implications for all aspects of behavior (see, e.g., Keele, 1987; MacKay, 1987). However, the only published studies of sequencing and aging (Allen, Madden, Weber, \& Crozier, 1992; Maylor, Vousden, \& Brown, 1999) have focused on episodic recall of letter strings. The present study extends the scope of aging and sequencing research with a task that does not require episodic recall and a focus on two types of sequential processes within short, highly familiar words: Lashley sequencing and contextbased sequencing.

\section{Lashley Sequencing}

Lashley sequencing concerns the mechanisms whereby speakers produce familiar speech units in proper order (when they do) and incorrect order (as in anticipation and perseveration errors). To examine effects of aging on Lashley sequencing, we compared sequential versus nonsequential speech errors in young and older adults. In sequential speech errors, an intended unit gets activated but in the wrong sequential position, as in the anticipations illustrated earlier. In nonsequential speech errors, a unit originating outside the intended utterance substitutes a unit of the same type in the same sequential position in the utterance. For example, if the intended utterance is Put it on the table, and the speaker says "Put it on the dable," the /d/ originates outside the intended utterance and substitutes $/ \mathrm{t} / \mathrm{at}$ the same point in the syllable, indicating a nonsequential speech error. If Lashley sequencing represents a special age-linked problem, we reasoned that older adults should produce more sequential than nonsequential speech errors relative to young adults.

\section{Context-Based Sequencing}

In context-based sequencing, choice of one unit in a production plan depends on the nature of units occurring earlier or later in the sequence. For example, speakers produce the article "a" as "an" if the immediately subsequent word begins with a vowel, an instance of context-based sequencing. The present study focused on the context-based sequencing that occurs when speakers add suffixes to familiar English words. For example, the regular plural suffix is /-z/ for nouns ending in voiced stops (e.g., /b/, /d/, and /g/) but /-s/ for nouns ending in unvoiced stops (e.g., /p/, /t/, and $/ \mathrm{k} /$ ). The main evidence that context-based sequencing occurs online during everyday speech production is that speakers automatically produce phonological accommodations that prevent speech errors from violating such morphological constraints. By way of illustration, consider the speech error /trak kav z/ ("track cows") instead of intended cow tracks (from Fromkin, 1973; see MacKay, 1979, for examples from German). Here two word-stems ("cow" and "track") have interchanged, a standard error type. However, this error triggered introduction of a new suffix, /-z/ instead of the original /-s/, an instance of phonological accommodation that preserves the constraints of English plural formation. We reasoned that response times should be longer and errors more frequent for responses that do versus do not require phonological accommodation, especially for older adults if context-based sequencing represents an age-linked problem.

\section{Speech Errors and the Transmission Deficit Hypothesis}

Under the transmission deficit hypothesis (e.g., MacKay \& Burke, 1990), cognitive aging weakens existing connections between nodes or memory representations in all cognitive systems, reducing the transmission across these connections of excitatory and inhibitory activity (theoretically defined). This transmission deficit hypothesis has been embedded within a connectionist framework known as node structure theory (NST; e.g., MacKay, 1987, 1990), which postulates a vast network of interconnected nodes that, in the case of verbal information, are organized into a semantic system representing, for example, word meanings, a phonological system representing speech sounds, and an orthographic system representing visual form and spelling. Original to NST, the same morphological and phonological nodes are used in perception and comprehension or meaning retrieval (via bottom-up connections) and production or retrieval of phonology and orthography (via top-down connections) (see also Dell, 1990; Rapp \& Goldrick, 2000). 
Nodes function by means of four fundamental processes within NST: node priming, node activation, linkage strength, and binding. Binding processes are necessary for forming the nodes and connections required to represent newly encountered information at any age. The node priming process is necessary for node activation but is parallel in nature, summates over time, and spreads automatically to connected nodes, increasing the availability of this related information. Priming transmission requires no special triggering mechanism and varies with the linkage strength of a connection and its distance (number of intervening connections) from an active node. Node priming also summates across all simultaneously active connections to a given node. Unlike priming, node activation provides the basis for consciousness and for production or retrieval, has fixed (all-or-none) intensity, proceeds serially, and is triggered by a special device that activates the most primed node in a domain (a set of nodes with identical sequential privileges of occurrence, e.g., vowels in the phonological system). This node activation principle is known as "most-primed-wins" and plays a central role in all speech errors under NST. Linkage strength of a connection determines the rate of priming transmission and varies with three factors: how recently a node has been activated, how frequently it has been activated over one's lifetime, and aging. Under NST, age-linked transmission deficits slow the binding process but do not influence engrainment learning, the process whereby recent and frequent use of existing connections augments linkage strength (see, e.g., MacKay \& Burke, 1990).

To illustrate the priming and activation processes underlying normal, error-free word production, consider the hierarchy of nodes in Figure 1 for producing plush (see MacKay, 1987, pp. $39-61$, for further details). The lexical node for plush first receives top-down priming from semantic system nodes representing, for example, luxurious and lavish and becomes activated as the mostprimed node in its domain (here the set of nodes representing adjectives). Once activated, the plush node strongly primes its connected phonological nodes, and $p l$ (initial consonant group) becomes activated as the most primed node in the (initial consonant group) domain. Once activated, the $p l$ node strongly primes

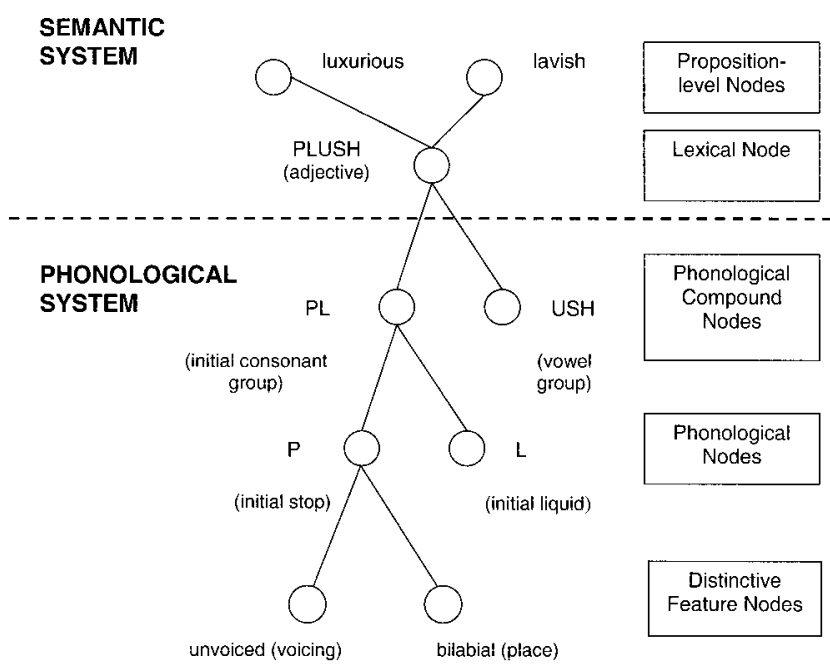

Figure 1. A subset of the nodes and connections for producing the adjective plush in node structure theory (see text for explanation). its connected phonological nodes, and $p$ (initial stop) becomes activated as the most primed node in the (initial stop) domain. Finally, activating $p$ (initial stop) strongly primes its connected feature nodes, which become activated and trigger the muscle movements for the $/ \mathrm{p} /$ in plush.

Under NST, omission errors depend on fundamentally different conditions from addition and nonsequential substitution errors. Speakers omit intended segments when the activating mechanism for a phonological domain is applied, but no node in the domain has received sufficient priming to become activated. If this happens for higher level phonological units such as the syllables in a word, then all constituent segments of the syllables will disappear from the final (internally or overtly generated) phonological output, as often occurs during a tip-of-the-tongue state when the mind goes completely blank and no phonological units can be retrieved (Burke et al., 1991). However, if a lower level node representing, for example, the $/ 1 /$ in plush receives insufficient priming, a singlesegment omission will result, as in "push ... I mean, plush."

Because the insufficient priming that causes omission errors reflects transmission deficits, which increase with aging, NST predicts an age-linked increase in omissions for phonological units at every hierarchic level. However, NST predicts an age-linked decrease in additions and nonsequential substitution errors, which reflect excess priming, a more likely occurrence for young adults (who do not suffer from age-linked transmission deficits). To illustrate, for the nonsequential substitution of "dable" for table, the /d/ node received more priming than the correct or intended /t/ in its (initial stop) domain and became activated in error under the most-primed-wins principle. Similarly, when gold was misproduced as "golden," the /-en/ suffix (not part of the intended sequence) received excessive priming and became activated, causing an addition error.

NST also predicts an age-linked increase in errors involving the right branch in a syllable hierarchy (representing the last segment in a syllable) versus the left branch (representing the first segment in a syllable). The reason is that, compared with the first segment, the last segment will receive relatively less top-down priming for older adults than young adults. To illustrate, consider the top-down connections for producing the CVC syllable pick, where /p/ terminates the left branch in the syllable structure and $/ \mathrm{k} /$ terminates the right branch. A single top-down connection directly links the pick node to $/ \mathrm{p} /$, whereas two intervening top-down connections link pick (indirectly via /ik/) to /k/ (see the vowel group in Figure 1; for syllable structure evidence, see, e.g., MacKay, 1972, 1987, pp. 62-89). As a result, two connections are vulnerable to transmission deficits when producing final $/ \mathrm{k} /$, but only one connection is vulnerable when producing initial /p/. Because transmission of top-down priming relates directly to error probability under the most-primed-wins principle, this means that omissions will be less likely for initial $/ \mathrm{p} /$ than final $/ \mathrm{k} /$, especially for older adults suffering from transmission deficits. By generalizing this example, NST predicts a greater age-linked increase in omissions for segments terminating right than left branches in a syllable body.

\section{The Present Research Paradigm: Relations to Our Theoretical Issues}

To elicit speech errors, we modified the transform technique of MacKay (1978): Participants saw visually presented words that 
sometimes contained either a /p/ or a /b/, and for words containing these "critical consonants" the task was to change the $/ \mathrm{p} /$ to $/ \mathrm{b} /$ or vice versa and produce the resulting word as quickly as possible. For example, if participants saw PUNK the correct response was "bunk", and if they saw RIB the correct response was "rip." In MacKay (1978), this technique elicited hundreds of speech errors involving critical and noncritical segments, as if changing one unit altered the stability of other units in the syllable. To allow assessment of general age-linked slowing, special difficulties with certain stimulus classes, and possible speed-accuracy trade-offs, we also measured response times in the present task.

To investigate Lashley sequencing (described earlier), the present study compared two types of errors that occur frequently in this paradigm: sequential versus nonsequential substitution errors. An example sequential substitution error in this task is nips misproduced as "pibs," 2 where the correct or intended unit /p/ was activated but in the wrong sequential position, as if the participant perceived that a b-to-p transform was required but transformed the wrong consonant (i.e., the initial rather than final consonant within the syllable body in nips). An example nonsequential substitution error is pug misproduced as "puck," where the unintended consonant $/ \mathrm{k} /$ substitutes $/ \mathrm{g} /$ in the same (syllable-final) position in the sequence. Under the hypothesis that aging influences Lashley sequencing, sequential substitutions should be especially common for older adults relative to nonsequential substitutions.

To investigate context-based sequencing (described earlier), the present study included words with two types of inflectional endings: critical versus noncritical inflections. Critical inflections required phonological accommodation because the syllable body ended in a critical consonant $(/ \mathrm{p} /$ or $/ \mathrm{b} /)$ followed by a regular plural or past tense suffix, e.g., RIBS /ribz/, and SOBBED /sa bd/. When participants change $/ \mathrm{b} /$ to $/ \mathrm{p} /$ in these stimuli, the suffixes must also change to maintain the phonological constraints of English morphology, from /-z/ to /-s/ for the RIBS-rips transformation, and from /-d/ to /-t/ for the SOBBED-sopped transformation. Noncritical inflections did not require phonological accommodation because the syllable body ended in a noncritical consonant (any stop other than $/ \mathrm{p} /$ or $/ \mathrm{b} /$ ) followed by a regular plural or past tense suffix ( e.g., POUNDED, BUGS). For such stimuli, correct responses (here "bounded" and "pugs") do not require a suffix change. If context-based sequencing represents a special age-linked problem, we reasoned that suffix omissions should be more common for stimuli with critical than noncritical inflections, especially for older adults.

\section{NST Predictions}

The transform technique enabled direct tests of the NST predictions discussed earlier plus three additional NST predictions. One concerned the probability of error correction. Under NST, the binding process for forming new connections plays a central role in error detection and correction (see MacKay, 1992), so that young adults will be more likely to detect and correct their errors than older adults because of age-linked deficits in forming new connections (MacKay \& Burke, 1990). Another NST prediction concerned the lexical bias effect, in which speech errors result in real words more often and nonwords less often than would be expected by chance (e.g., Baars et al., 1975; Dell, 1986). Under NST, lexical bias effects arise in part because new connections are required to represent and produce nonwords as coherent units, whereas word production only involves preformed connections (see e.g., MacKay \& James, 2001). Age-linked deficits in forming new connections will therefore reduce the likelihood that older adults will represent and produce nonwords such as "plood" under time pressure but will not affect production of real words such as "plod." In short, NST predicts a greater lexical bias effect in speech errors of older than young adults.

The final NST prediction concerned a subclass of stimuli that ended in plural or past tense suffixes (e.g., BINS, PANNED): Omission of these suffixes (e.g., pins misproduced as "pin") was a common type of error in MacKay (1978). These suffix omissions are theoretically important because of how words containing plural and past tense suffixes are represented and produced in NST. For example, a single node represents the word bill in the semantic system under NST, whereas three nodes represent its plural: the bill node, a node representing the concept $P L U R A L^{3}$ in the domain suffix, and a node representing the conjunction of bill and $P L U$ $R A L$ (for relevant data, see MacKay, 1979). This means that when participants in the current task substitute /p/ for /b/ in BILLS, a new connection must be formed to link the resulting pill with the concept PLURAL so that the correct response "pills" can be produced. As a consequence, NST predicts that omissions will be more likely for suffixes than for other syllable-final consonants, especially for older adults, because of age-linked deficits in forming new connections (see MacKay \& Burke, 1990).

\section{Other Theoretical Frameworks}

The present study also addressed several other theoretical frameworks. One concerned a controversy between two general classes of theories for explaining speech errors: interactive activation theories versus serial-stage theories. Interactive activation theories (e.g., Dell, 1986; Harley, 1984; MacKay, 1987) assume that phonological processes can interact with word-level factors such as lexical status and frequency to influence lexical retrieval, as in the lexical bias effect in speech errors. By contrast, serialstage theories (e.g., Fromkin, 1970; Levelt et al., 1991) assume that lexical retrieval occurs in two independent stages: retrieval of semantic and syntactic information followed by retrieval of phonological form, with no retroactive effects of phonology on wordlevel factors. Serial-stage theories predict no more word errors than would be expected by chance for either young or older adults. However, interactive-activation and serial-stage theories only apply if the current error-induction task involves lexical-level processing, which we will show in a subsidiary analysis involving effects of word frequency.

The present study also tested predictions derived from editor theories, in which an internal editor detects self-produced errors using normal language perception mechanisms and corrects these

\footnotetext{
${ }^{2}$ We illustrate errors in the transform paradigm in the same way as errors in everyday speech discussed earlier: The error appears in quotes, and the intended (correctly transformed) output appears in italics. A reverse transformation of the critical segment in the intended output suffices to derive the original stimulus word, in this case, NIBS.

${ }^{3}$ Superordinate units that represent a set of alternative phonological units are capitalized in italics. For example, PLURAL represents the three possible suffixes for forming regular plurals in English.
} 
errors using normal language production mechanisms (e.g., Levelt, 1989, pp. 458-497). If the internal editor becomes less efficient with aging, editor theories not only predict an age-linked decrease in error correction but make additional predictions to be discussed in connection with the present results. The present study also tested predictions derived from the Dell et al. (1997) theory (an agelinked increase in "bad" perseveratory errors, and an age-linked decrease in "good" anticipatory errors). Finally, we contrasted NST with other theories that predict across-the-board rather than selective effects of aging on speech errors. For example, Myerson, Hale, Wagstaff, Poon, and Smith (1990) assume that aging degrades all mental processes to the same extent and predict that all types of speech errors will increase with aging in the current paradigm.

\section{Method}

\section{Participants}

Participants were 32 young $(M=19.1$ years, $S D=1.2$, range $=18-22)$ and 32 older $(M=72.4$ years, $S D=3.1$, range $=67-79)$ native English speakers with self-reported corrected-to-normal visual acuity. Older adults were paid for participating, and young adults received credit in introductory psychology courses. After signing a consent form, participants answered a set of demographic questions and completed the Nelson-Denny Vocabulary test (maximum $=25)$ and Forward and Backward Digit Span tests. Vocabulary scores were lower for young adults $(M=15.5, S D=2.3)$ than older adults $(M=21.6, S D=1.8), t(58)=11.38, p<.01$, as were years of education (young, $M=13.5, S D=1.2$; older, $M=16.6, S D=$ 3.1 ), $t(58)=5.23, p<.01$. Forward digit span (young, $M=9.1, S D=1.2$; older, $M=8.6, S D=1.3)$ did not differ by age ( $p=.19$ ), but young adults had marginally higher backward digit spans $(M=7.7, S D=1.4)$ than older adults $(M=7.0, S D=1.3 ; p=.08)$.

\section{Materials and Design}

Materials were 48 practice words, 20 control words, and 156 experimental words consisting of a suffix (optional) plus a single syllable with either CVC, VCC, CCVC, or CVCC structure, where C stands for a consonant and $\mathrm{V}$ stands for a long or short vowel. Experimental words contained a single "critical consonant," /p/ or /b/, and came in pairs formed by substituting $/ \mathrm{p} /$ for $/ \mathrm{b} /$ or vice versa. Participants saw one but not both members of a word pair in counterbalanced fashion, so that the correct response for half the participants was the stimulus word for the remaining participants and correct transformation of the $/ \mathrm{p} /$ to $/ \mathrm{b} /$ or vice versa always resulted in another word (e.g., PUNK-bunk; BINS-pins). To prevent possible biases in participants' search for voiced versus unvoiced features in experimental words, as many noncritical consonants were voiced as unvoiced, and each participant saw an equal number of words containing $/ \mathrm{p} /$ versus $/ \mathrm{b} /$.

The critical consonants occurred in word-initial position (e.g., BEG$p e g$ ), word-final position (e.g., LAB-lap), or next-to-final position (e.g., RIPPED-ribbed). Thirty-three of the 78 experimental word pairs ended in plural or past tense suffixes that fell into two categories: critical inflections, in which the suffix followed a critical segment $(N=13$; e.g., gapped, $c a b s)$, and noncritical inflections, in which the suffix followed a noncritical segment $(N=20$; e.g., bugs, parred $)$. To produce a real word after changing the $/ \mathrm{p} /$ to $/ \mathrm{b} /$ or vice versa (as instructed), phonological accommodation was unnecessary for noncritical inflections but necessary for critical inflections since unvoiced suffixes $(/-\mathrm{s} /$ or $/ \mathrm{t} / \mathrm{t})$ follow $/ \mathrm{p} /$ but voiced suffixes (/-z/ or /-d/) follow /b/ in phonologically permissible words. To equate the mean frequency of words containing $/ \mathrm{p} /$ versus $/ \mathrm{b} /$, we used Francis and Kucera (1982).
The control words also came in pairs $(N=10)$ that were counterbalanced across participants but contained $/ \mathrm{k} /$ or $/ \mathrm{t} /$ rather than $/ \mathrm{p} /$ and $/ \mathrm{g} /$ or /d/ rather than /b/ so as to discourage strategies involving exclusive focus on the critical consonants. Control pairs were formed by substituting $/ \mathrm{k} /$ for /g/ and /t/ for /d/ or vice versa (e.g., COLD-GOLD; TUNE-DUNE).

\section{Procedure}

Participants were instructed that they would see words in capital letters, some of which contained either $[\mathrm{P}]$ as in PIG or $[\mathrm{B}]$ as in BIG. If they saw a word containing $[\mathrm{P}]$, their task was to mentally change the $[\mathrm{P}]$ to $[\mathrm{B}]$ and produce the resulting word as quickly as possible into the microphone. If they saw a word containing [B], their task was to mentally change the [B] to $[\mathrm{P}]$ and produce the resulting word as quickly as possible. If the word contained neither [P] nor [B] (for control words such as DUNE), their task was to say "neither" as quickly as possible. Each participant saw 24 practice words followed by 88 randomly ordered experimental and control stimuli.

The experiment was run on a Macintosh Power PC using Psyscope software. A voice key timer determined the time to begin to say the transforms. To initiate each trial, participants pressed a "go" key, displaying a string of asterisks for $200 \mathrm{~ms}$ followed by a stimulus word in 24-point Chicago font for $80 \mathrm{~ms}$ and then a string of question marks that disappeared after the participant's vocal response. To ensure correct perception of the stimuli, participants next saw and answered a "yes-no" question (e.g., "Did you see BAIL?"). The experimenter recorded these "yes-no" responses on an answer sheet and scored trials with "no" responses as misperceptions. Sessions were tape recorded, and speech errors were later transcribed from the tapes. An assistant initially transcribed the tapes unaware of participant age, and Lori James then checked the transcribed responses against the tapes again unaware of participant age. All between-judge discrepancies were resolved before analysis.

\section{Results}

\section{Overall Error Frequency, Speed-Accuracy Analyses, and General Methodological Issues}

For all error analyses, we omitted participants with no data in one or more cells, so that different analyses involved differing numbers of participants. For analyses of overall error frequency, we defined speech errors as any incorrect response on valid trials, which excluded misperceptions and responses that were insufficiently audible to score from the tapes. For the 78 experimental stimuli, valid trials were more common for young adults $(M=$ $72.8, S D=3.1)$ than older adults $(M=67.2, S D=5.5), t(62)=$ $4.98, p<.01$, and as a percentage of valid trials overall errors were more common for older $(M=16.1 \%, S D=11.0 \%)$ than young adults $(M=8.9 \%, S D=5.1 \%), t(62)=3.33, p<.01$. This general age-related increase in errors was not due to a speedaccuracy trade-off because errors yielded longer response times than correct responses for both young and older adults: A 2 (age) $\times 2$ (response type: errors vs. correct responses) analysis of variance (ANOVA) on response times for correct responses versus errors (excluding fluency problems) yielded a main effect of age, $F(1,60)=23.85, M S E=327,294, p<.01$, with slower response times for older than young adults, and a main effect of response type, $F(1,60)=33.04, M S E=89,482, p<.01$, with longer response times for errors than correct responses, and no Age $\times$ Response Type interaction $(F<1)$. Correct response times were longer for older adults $(M=1,417 \mathrm{~ms}, S D=386)$ than young 
adults $(M=946 \mathrm{~ms}, S D=172), t(61)=6.28, p<.01$, the usual age-linked slowing result.

On the basis of prior research, we next classified overall errors into nine types shown with examples in Table 1. Besides omissions, additions, and sequential and nonsequential substitutions (illustrated earlier), other error types included nontransformations (production without change of a presented word containing $/ \mathrm{p} /$ or /b/, e.g., the response "ribbed" for the stimulus RIBBED); nonidentification errors (the response "neither" for a stimulus containing a critical consonant, e.g., GABBED); fluency errors (stutters, "uh"s, and false starts); and multiple errors (involving several types of errors in combination, e.g., a fluency error combined with a nontransformation error as in "cu-cubs" for cups). In addition to such clear cases of dual category membership, multiple errors also included ambiguous and not-easily-classified examples that we labeled miscellaneous (e.g., "bow-powell-bow" for pole, and "stop...- neither" for slob). The final category involved three types of immediate error correction: one-time corrections (e.g., "scopped-sopped" for sopped), two-time corrections (e.g., "blushploosh-plush" for plush), and three-time corrections (e.g., "pl-ploplude-prude" for prude).

\section{Methodological Issues Associated With Relative Versus Absolute Error Analyses}

Table 1 provides two frequency analyses for the nine error types: absolute frequencies (percentage of valid trials with an error type) and relative frequencies (an error type as percentage of total errors) for young and older adults. Relative frequencies were useful because they factor out the greater overall error rate of older adults and because they are necessary in some cases. For example, error corrections required relative analyses (percentage of correc- tions on trials with errors) because an error must be committed for correction to occur. However, two general cases required analyses based on absolute error frequencies. Case 1 involved small error categories that required the addition of unambiguous instances of multiple and corrected errors (reclassified according to the error types involved) to ensure sufficient power. This meant abandonment of total errors as a denominator because the resulting error categories were no longer mutually exclusive and summed to more than $100 \%$. Case 2 required absolute frequency analyses for comparing stimulus classes that differed in number of stimuli or possible valid trials.

Although older adults committed more overall errors than young adults in absolute frequency, the nine error types differed in relative frequency for young versus older adults, indicating selective effects of aging. The relative frequency of omission errors was greater for older than young adults, $t(62)=3.03, p<.01$, but for most error types, age either had no effect on relative frequency or young adults were more error prone than older adults. Addition, sequential substitution, nonidentification, fluency, multiple, and corrected errors did not differ by age $(p s>.15)$, nonsequential substitutions were significantly more frequent for young than older adults, $t(62)=2.26, p<.05$, and nontransformation errors were marginally more frequent for young than older adults, $t(62)=$ $1.81, p=.08$.

\section{Relations Between Aging and Sequencing}

\section{Sequential Versus Nonsequential Substitution Errors}

Absolute error analyses were required to achieve sufficient power for comparing sequential versus nonsequential substitution errors (including unambiguous multiple and corrected errors on

Table 1

Absolute and Relative Frequencies of Error Types on Experimental Trials for Young and Older Adults

\begin{tabular}{|c|c|c|c|c|c|c|c|c|c|}
\hline \multirow[b]{3}{*}{ Error type } & \multirow{3}{*}{$\begin{array}{l}\text { Examples of error } \\
\text { responses }(\rightarrow=\text { was } \\
\text { misproduced as })\end{array}$} & \multicolumn{4}{|c|}{$\begin{array}{l}\text { Absolute frequency } \\
\text { (\% of valid trials) }\end{array}$} & \multicolumn{4}{|c|}{$\begin{array}{l}\text { Relative frequency } \\
\text { (\% of total errors) }\end{array}$} \\
\hline & & \multicolumn{2}{|c|}{ Young } & \multicolumn{2}{|c|}{ Older } & \multicolumn{2}{|c|}{ Young } & \multicolumn{2}{|c|}{ Older } \\
\hline & & $M$ & $S D$ & $M$ & $S D$ & $M$ & $S D$ & $M$ & $S D$ \\
\hline Omission errors & $\begin{array}{l}\text { pans } \rightarrow \text { "pan" } \\
\text { breach } \rightarrow \text { "beach" }\end{array}$ & 0.3 & 0.6 & 2.0 & 2.7 & 2.6 & 7.8 & 12.5 & 16.7 \\
\hline Addition errors & $\begin{array}{l}\text { lip } \rightarrow \text { "lips" } \\
\text { cups } \rightarrow \text { "clups" }\end{array}$ & 0.6 & 1.2 & 1.0 & 1.6 & 5.7 & 9.7 & 5.4 & 7.4 \\
\hline Sequential substitution errors & $\begin{array}{l}\text { labs } \rightarrow \text { "baps" } \\
\text { beg } \rightarrow \text { "peb" }\end{array}$ & 0.1 & 0.4 & 1.0 & 2.8 & 1.5 & 5.0 & 6.5 & 19.1 \\
\hline Nonsequential substitution errors & $\begin{array}{l}\text { pug } \rightarrow \text { "puck" } \\
\text { jips } \rightarrow \text { "jipped" }\end{array}$ & 1.9 & 2.0 & 1.4 & 2.1 & 22.0 & 25.3 & 10.5 & 13.6 \\
\hline Nontransformation errors & $\begin{array}{l}\text { ripped } \rightarrow \text { "ribbed" } \\
\text { mops } \rightarrow \text { "mobs" }\end{array}$ & 1.1 & 1.2 & 1.6 & 1.7 & 17.0 & 23.8 & 8.8 & 9.6 \\
\hline Nonidentification errors & $\begin{array}{l}\text { gapped } \rightarrow \text { "neither" } \\
\text { tab } \rightarrow \text { "neither" }\end{array}$ & 0.5 & 0.9 & 0.6 & 1.4 & 5.0 & 8.6 & 3.4 & 8.4 \\
\hline Fluency errors & $\begin{array}{l}\text { flap } \rightarrow \text { "f-flap" } \\
\text { bugs } \rightarrow \text { "um bugs" }\end{array}$ & 1.4 & 2.7 & 2.9 & 3.6 & 13.4 & 20.8 & 17.9 & 23.6 \\
\hline Multiple errors & $\begin{array}{l}\text { pun } \rightarrow \text { "uh bups-bun" } \\
\text { gapped } \rightarrow \text { "grabbed" }\end{array}$ & 1.4 & 1.6 & 2.7 & 3.8 & 15.2 & 16.1 & 15.1 & 19.8 \\
\hline Error corrections & $\begin{array}{l}\text { slob } \rightarrow \text { "lop-plop-slob" } \\
\text { plush } \rightarrow \text { "ploosh-plush" }\end{array}$ & 1.5 & 1.7 & 2.9 & 3.6 & 17.7 & 19.2 & 19.9 & 21.9 \\
\hline
\end{tabular}


control and experimental trials). Table 2 shows the number and percentage of valid trials with sequential substitution errors, in which the correct critical segment was produced in the wrong sequential position (e.g., nips misproduced as "pibs"). Sequential substitutions involved anticipation or prepositioning of the critical segment (e.g., cup misproduced as "bup") more often than perseveration or postpositioning of the critical segment (e.g., pit misproduced as "pib"; $78 \%$ vs. $22 \%$ ). Young adults produced too few anticipations (1) and perseverations (5) to detect a reliable pattern, but the pattern for older adults ( $86 \%$ vs. $14 \%$ ) was almost identical to the relative frequency of anticipations and perseverations in everyday speech (e.g., $87 \%$ vs. $13 \%$ in Garnham, Shillcock, Brown, Mill, \& Cutler, 1982). These results do not support the Dell et al. (1997) predictions (i.e., an age-linked increase in perseveratory errors and an age-linked decrease in anticipatory errors). ${ }^{4}$

Table 2 also shows the frequency of nonsequential substitutions, in which a segment outside the sequence replaced an intended segment (e.g., pug misproduced as "puck"). A 2 (age) $\times 2$ (substitution type: sequential vs. nonsequential) ANOVA on Table 2 data yielded a main effect of age, $F(1,62)=4.14, M S E=.0011$, $p<.05$, with more errors for older than young adults, a main effect of substitution type, with more nonsequential than sequential errors, $F(1,62)=4.77, M S E=.00071, p<.05$, and a marginal Age $\times$ Substitution Type interaction, $F(1,62)=3.81, M S E=$ $.00071, p=.06$, which reflected an age-linked increase in sequential substitutions, $t(62)=2.47, p<.05$, but no age difference for nonsequential substitutions $(t<1)$. This selective age-linked increase in sequential but not nonsequential substitution errors suggests that Lashley sequencing may represent a special problem for older adults.

\section{Critical Versus Noncritical Inflections}

Response times. As far as could be determined from the audiotapes, participants always changed the suffix in words with

Table 2

Number and Percentage of Valid Experimental and Control Trials Involving Sequential and Nonsequential Substitution Errors for Young and Older Adults

\begin{tabular}{|c|c|c|}
\hline Error type & Young adults & Older adults \\
\hline \multicolumn{3}{|c|}{ Experimental condition } \\
\hline \multicolumn{3}{|l|}{ Sequential substitution errors } \\
\hline No. of errors & 6 & 43 \\
\hline Mean $\%$ of valid trials with errors & $0.3(0.6)$ & $2.0(4.6)$ \\
\hline \multicolumn{3}{|l|}{ Nonsequential substitution errors } \\
\hline No. of errors & 63 & 58 \\
\hline Mean $\%$ of valid trials with errors & $2.7(2.6)$ & $2.7(2.8)$ \\
\hline \multicolumn{3}{|c|}{ Control condition } \\
\hline \multicolumn{3}{|l|}{ Sequential substitution errors } \\
\hline No. of errors & 6 & 16 \\
\hline Mean $\%$ of valid trials with errors & $2.4(5.2)$ & $8.3(12.0)$ \\
\hline \multicolumn{3}{|l|}{ Nonsequential substitution errors } \\
\hline No. of errors & 0 & 4 \\
\hline Mean $\%$ of valid trials with errors & $0.0(0.0)$ & $2.2(6.8)$ \\
\hline
\end{tabular}

Note. Standard deviations appear in parentheses. critical inflections (e.g., transforming stimulus LAPS to /labz/ rather than /labs/, which contains the impermissible word-final sequence /-bs/). The consistent nature of this pattern suggests that both young and older adults automatically applied rules for changing plural and past tense suffixes so as to achieve voicing agreement with the syllable-final segment, even for the "newly imported" syllable-final segments in the present task. However, producing these phonological accommodations incurred a time cost that was greater for older than young adults. Figure 2 (left panel) shows the mean correct response times by age group for words containing critical versus noncritical inflections. A 2 (age) $\times 2$ (inflection type: critical vs. noncritical) ANOVA on these data yielded a main effect of inflection type, $F(1,61)=$ $52.58, M S E=35,533, p<.01$, with longer response times for critical than noncritical inflections, a main effect of age, $F(1$, $61)=32.51, M S E=192,603, p<.01$ (general slowing), and an Age $\times$ Inflection Type interaction, $F(1,61)=17.80, M S E=$ $35,533, p<.01$, that reflected a large age-linked increase in response times for critical inflections, $t(61)=5.73, p<.01$, and a reliable but smaller age-linked increase for noncritical inflections, $t(62)=4.99, p<.01$. These age-linked differences in response times for producing critical versus noncritical inflections suggest that context-based sequencing processes may represent a special problem for older adults.

Errors. Stimuli with critical versus noncritical inflections differed in number and required absolute error analyses to achieve sufficient power. Figure 2 (right panel) shows the mean percentage of valid trials in which young and older adults omitted or substituted segments in words containing critical versus noncritical inflections. A 2 (age) $\times 2$ (inflection type: critical versus noncritical) mixed ANOVA on these data yielded a main effect of age, $F(1,62)=9.20, M S E=.016, p<.01$ (with more errors for older than young adults), no main effect of inflection type $(F<1)$, and an Age $\times$ Inflection Type interaction, $F(1,62)=8.78, M S E=.0097, p<.01$. This interaction reflected an age-linked increase in errors on critical inflections, $t(62)=3.58, p<.01$, but not on noncritical inflections $(p>.20$; see Figure 2). Separate analyses for errors on the inflections per se versus other segments in the syllable body of inflected stimuli yielded similar results. For example, more errors occurred for older than young adults on critical inflections per se, $t(62)=2.40, p<.05$, but not on noncritical inflections $(p>.16)$. Like the response time data, these error data suggest that context-based sequencing processes represent a special problem for older adults, at least for suffix choice after "experimentally imported" units.

\footnotetext{
${ }^{4}$ It might be argued that the general tendency of older adults to mistransform critical consonants in noninitial syllabic position is confounded for anticipation errors (e.g., nips misproduced as "pibs" because the stimulus NIBS contains a noninitial critical consonant). However, this suggestion overlooks the fact that anticipation errors occurred in initial syllabic position in the present task and involved production of the correctly transformed critical consonant. It is nevertheless possible that the Dell et al. (1997) theory applies to anticipation and perseveration errors that occur between but not within words and syllables.
} 


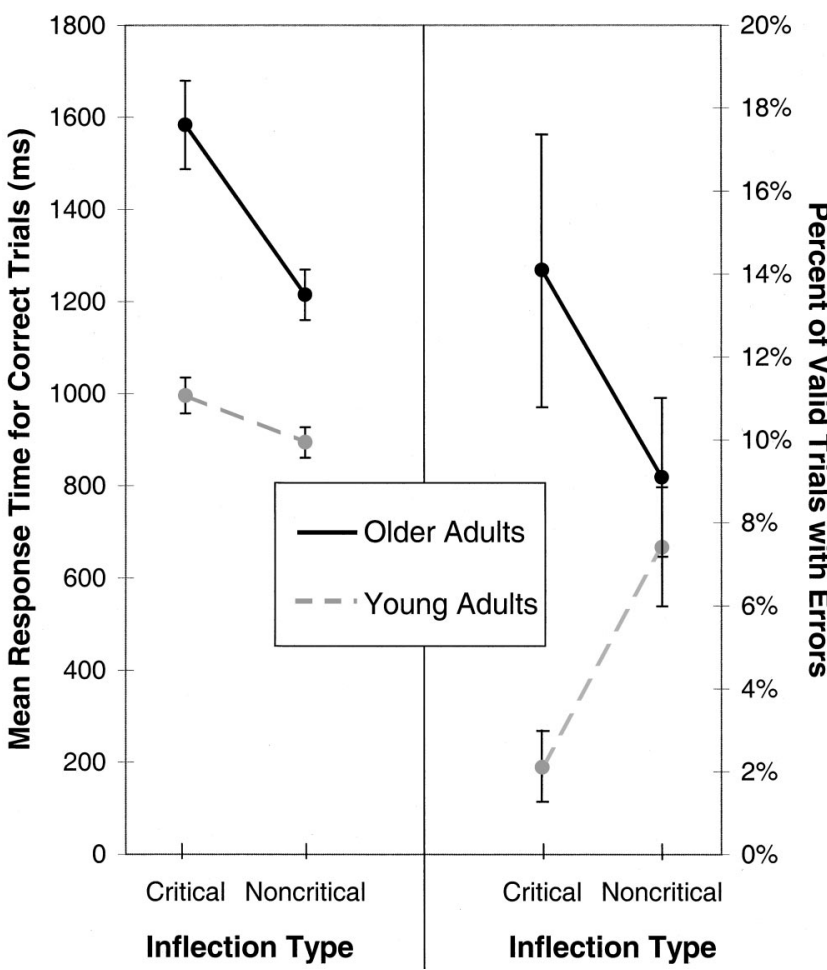

Figure 2. Response times (left panel) and mean percentage of valid trials involving errors (right panel) on critical versus noncritical inflections for young and older adults. Error bars represent $\pm 1 S E$.

\section{Tests of NST Predictions}

\section{Omission Versus Addition and Nonsequential Substitution Errors}

Because relative frequency analyses were possible in comparing omissions versus additions and nonsequential substitutions (a theoretically based combination), Figure 3 shows the frequency of these error categories as a percentage of total errors for young and older adults. A 2 (age) $\times 2$ (error type: omissions vs. combined additions and nonsequential substitutions) ANOVA on these data yielded no age effect $(F<1)$ but an error-type effect, $F(1,62)=$ $16.93, M S E=.041, p<.01$, together with an Age $\times$ Error Type interaction, $F(1,62)=8.48, M S E=.041, p<.01$. As predicted under NST, this interaction reflected an age-linked increase in omissions, $t(62)=3.03, p<.01$, but a marginal age-linked decrease in combined additions and nonsequential substitutions, $t(62)=1.86, p=.07$ (see Figure 3 ).

\section{Error Outcomes: Words Versus Nonwords}

Absolute error analyses were required to achieve sufficient power for comparing word versus nonword errors (excluding only errors that had ambiguous lexical status or yielded words by definition, i.e., nonidentification and nontransformation errors). Figure 4 shows the mean percentage of valid experimental and control trials in which errors resulted in words versus nonwords for young and older adults. A 2 (age) $\times 2$ (error outcome: words vs. nonwords) mixed ANOVA on these data yielded an age effect,

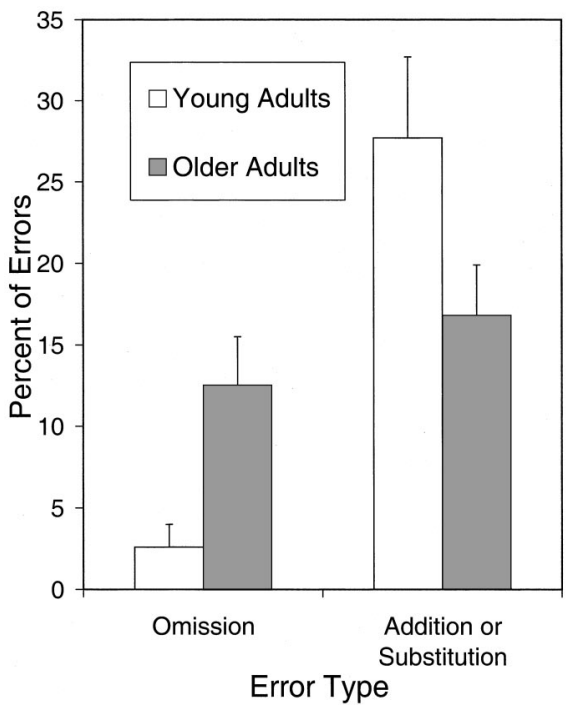

Figure 3. Mean percentage of errors on experimental trials that involved omission versus addition and nonsequential substitution of segments for young and older adults (with error bars representing $1 S E$ ).

$F(1,62)=10.23, M S E=.0018, p<.01$, with more errors for older adults; an effect of error outcome, $F(1,62)=33.95, M S E=$ $.00067, p<.01$, with more word than nonword errors; and an Age $\times$ Error Outcome interaction, $F(1,62)=10.75, M S E=$ $.00067, p<.01$. Consistent with NST prediction, this interaction arose because word errors were more common for older than young adults, $t(62)=3.67, p<.01$, but nonword errors did not differ by age $(p>.17)$. This interaction was not due to a floor effect for nonwords because one-sample $t$ tests indicated that mean errors on nonwords were significantly greater than 0 for both

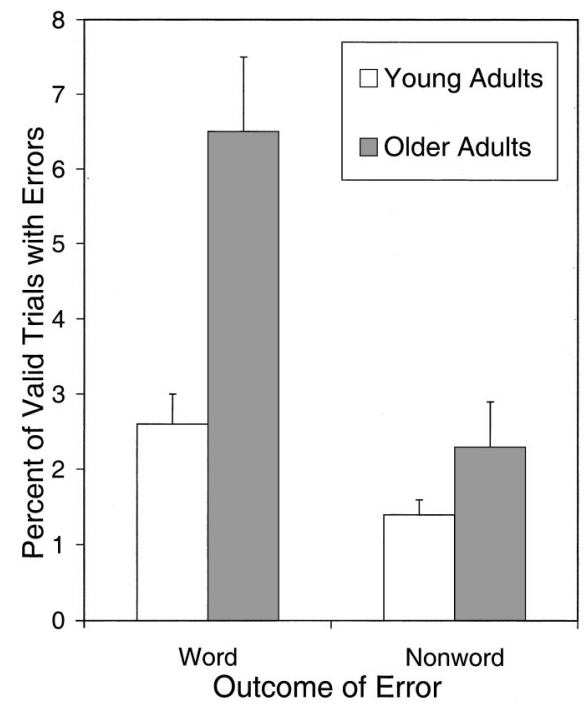

Figure 4. Mean percentage of valid experimental and control trials in which errors resulted in words versus nonwords for young and older adults (with error bars representing $1 S E$ ). 
young, $t(31)=6.11, p<.01$, and older adults, $t(31)=3.86, p<$ .01 .

Under an alternative to the NST account of this interaction, young adults produced fewer word errors because they responded more rapidly than older adults: According to Dell and Reich (1981), lexical bias effects diminish in magnitude when participants speak rapidly, allowing insufficient time for reverberative bottom-up and top-down priming to activate a word in error. Under this hypothesis, slower response times should accompany word than nonword errors for both young and older adults, and we tested this possibility by comparing response times for word versus nonword errors of the 16 young and 19 older adults who produced at least one unambiguous word and nonword error. A 2 (age) $\times 2$ (error outcome: word vs. nonword) ANOVA on these data indicated the usual age effect, $F(1,33)=12.60, M S E=488,994, p<$ .01 , but no difference between word versus nonword errors $(F<$ $1)$, and no Age $\times$ Error Outcome interaction $(p>.30)$. These data do not support the hypothesis that response times are slower for word than nonword errors and that the age-linked increase in word errors in the present paradigm was due to the slower response times of older adults.

Finally, to determine whether the overall lexical bias effect was reliable, we estimated the chance probability of a word error in three steps for each experimental word. In Step 1 we replaced each consonant with all possible English consonants and the vowel with all possible English vowels. Step 2 removed outcomes with phonologically impermissible sequences because all errors in the current study were phonologically permissible. Step 3 removed proper names and substitutions of $[\mathrm{P}]$ for $[\mathrm{B}]$ or vice versa (which, by design, resulted in correct responses). We then used the American Heritage Dictionary to determine the relative frequency of word versus nonword outcomes averaged across all stimuli. This chance frequency was $25 \%(S D=10 \%)$, and $95 \%$ of our participants produced a higher percentage of word errors than would be expected by chance; $5 \%$ did not. This difference was significant using sign test with participants as unit of analysis $(p<.01)$, indicating a significant lexical bias effect that replicates Dell (1986) using a different paradigm.

\section{Errors Involving Initial Versus Noninitial Consonants}

To test for predicted interactions between aging and errors in initial versus noninitial syllabic positions, we compared errors involving the critical consonants $/ \mathrm{p} /$ or $/ \mathrm{b} /$ at the beginning or end of the syllable body in our experimental stimuli (excluding suffix errors). Because these analyses included multiple and corrected errors, they were performed on percentage of valid trials (rather than percentage of all errors). Figure 5 shows the mean percentage of valid experimental trials in which critical consonant errors of young versus older adults involved initial versus noninitial syllable positions. A 2 (age: young vs. older) $\times 2$ (error position: initial vs. non-initial) ANOVA on these data indicated an effect of age, with more errors for older than young adults, $F(1,62)=8.00, M S E=$ $.0013, p<.01$, and an Age $\times$ Error Position interaction, $F(1$, 62) $=4.79, M S E=.00089, p<.05$. Consistent with NST prediction, this interaction reflected an age-linked increase in errors on noninitial critical consonants, $t(62)=2.92, p<.01$, but no age difference for initial critical consonants $(p>.28)$.

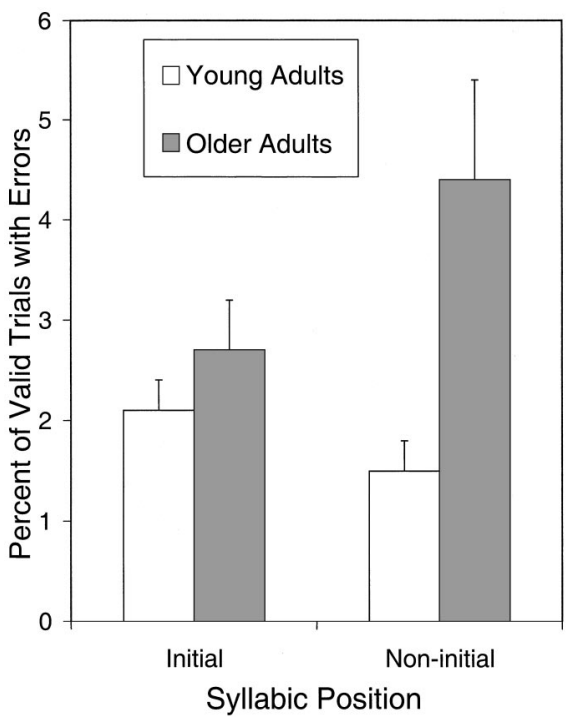

Figure 5. Mean percentage of valid experimental trials with errors in initial versus noninitial syllable positions for young and older adults (with error bars representing $1 S E$ ).

\section{Errors Involving Inflectional Versus Noninflectional Endings}

For both young and older adults, consonant errors more often involved suffixes than other consonants in word-final position. Because stimuli with suffixes versus other word-final consonants differed in number, absolute error analyses were required. Table 3 shows the mean percentage of valid trials in which young and older participants omitted or substituted suffixes versus other word-final consonants in uninflected stimuli. A 2 (age) $\times 2$ (consonant type: inflectional vs. noninflectional) ANOVA on these data yielded an effect of consonant type, $F(1,62)=14.08, M S E=$ $.0019, p<.01$, with more errors on inflectional than noninflectional consonants; an age effect, $F(1,62)=7.94, M S E=.0017$, $p<.01$, with more errors for older than young adults; and a trend toward an Age $\times$ Consonant Type interaction, $F(1,62)=2.68$, $M S E=.0019, p=.11$, resulting from a reliable age effect for suffixes, $t(62)=2.32, p<.05$, but not for syllable-final segments $(p>.11)$. The main effect of consonant type indicates that suffixes are more error prone than other word-final consonants, consistent with NST prediction. The reliable age effect for suffixes but not syllable-final segments also comports with NST prediction.

\section{Error Corrections}

Young and older adults immediately corrected many of their errors, and Table 4 shows the percentage of corrected errors for young and older adults on valid experimental and control trials. For the 18 young and 20 older participants who committed errors on control trials, corrections were more frequent for young than older adults, $t(36)=2.67, p<.05$, a result consistent with predictions of NST and editor theories and with age-linked declines observed in phonological error detection (Mahoney, 1997), orthographic error correction (Shafto, 2002), keypress error correction (Rabbitt, 1990), and lexical error correction in a route- 
description task (Valencia-Laver, 1992), in which young adults corrected more lexical substitution errors (e.g., "Turn left, I mean, right") than older adults.

However, multiple corrections were less frequent for young than older adults combined across experimental and control trials, $\chi^{2}(1$, $N=21)=5.36, p<.05,{ }^{5}$ and corrections on experimental trials (which included data from all participants) did not differ by age either overall $(t<1)$ or for separate analyses of single and multiple corrections (see Table 4). Editor theories suggest an interesting post hoc account of this age-linked difference between control versus experimental trials. Under this account, an internal editor detected and corrected errors for young and older adults, but only young adults adjusted the detection criterion of their internal editor based on the instructions. Because the instructions called for no change in control words, the young adults adjusted their editor to detect any self-produced modification of control words. However, because the instructions called for a specific $\mathrm{p} / \mathrm{b}$ change in experimental words, the young adults adjusted their editor to focus on errors involving $\mathrm{p} / \mathrm{b}$, allowing non-p/b errors to pass undetected. This hypothesis predicts a higher probability of error correction for critical segments $(p / b)$ than other units, especially for young adults. Because the internal editor engages normal perceptual mechanisms for error detection and normal production mechanisms for error correction (Levelt, 1989, pp. 458-497), editor theories also predict an interesting error correction phenomenon arising from age-linked asymmetries between production versus perception (noted earlier; see Burke et al., 2000, for a review). Because of age constancy in perception, older adults will often detect an error but make another error during correction as a result of age-linked deficits in production. This will cause an age-linked increase in the relative frequency of three-time versus two-time corrections for multiple corrections of young versus older adults.

However, the present results supported neither of these predictions. As a proportion of multiple corrections, two-time corrections were relatively more frequent than three-time corrections for older ( $83 \%$ vs. $17 \%$ ) than young adults (66\% vs. $33 \%)$, and an analysis of how often participants corrected errors on critical versus noncritical segments in experimental words (excluding fluency errors) did not yield the predicted age interaction. A 2 (age) $\times 2$ (error locus: critical vs. noncritical segments) on these data indicated no main effect of age $(F<1)$ but a main effect of error locus, with more error corrections on critical than noncritical segments, $F(1$, $53)=5.48, M S E=.087, p<.05$, and a marginal Age $\times$ Error Locus interaction, $F(1,53)=3.31, M S E=.087, p=.07$, which reflected more error corrections on critical than noncritical segments for older adults, $t(26)=3.95, p<.01(M=32 \%, S D=$

Table 3

Percentages of Valid Experimental Trials With Omission and Nonsequential Substitution Errors on Suffixes Versus Other Syllable-Final Segments for Young and Older Adults

\begin{tabular}{|c|c|c|c|c|}
\hline \multirow[b]{2}{*}{ Error type } & \multicolumn{2}{|c|}{$\begin{array}{l}\text { Young } \\
\text { adults }\end{array}$} & \multicolumn{2}{|c|}{$\begin{array}{l}\text { Older } \\
\text { adults }\end{array}$} \\
\hline & $M$ & $S D$ & $M$ & $S D$ \\
\hline Suffix errors & 2.2 & 2.8 & 5.5 & 7.6 \\
\hline Other errors involving syllable-final segments & 0.5 & 1.1 & 1.3 & 2.4 \\
\hline
\end{tabular}

Table 4

Percentages of Errors That Were Corrected by Age on Valid Experimental and Control Trials, Overall and by Correction Type (Single vs. Multiple Corrections)

\begin{tabular}{cccccc}
\hline & \multicolumn{2}{c}{ Experimental trials } & & \multicolumn{2}{c}{ Control trials } \\
\cline { 2 - 3 } \cline { 5 - 6 } $\begin{array}{c}\text { Correction } \\
\text { type }\end{array}$ & Young adults & Older adults & & Young adults & Older adults \\
\hline $\begin{array}{c}\text { Overall } \\
M\end{array}$ & 17.7 & 19.9 & & 47.2 & 14.6 \\
$S D$ & 19.2 & 21.9 & & 46.9 & 26.7 \\
$\begin{array}{c}\text { Single } \\
M\end{array}$ & 15.7 & 16.4 & & 47.2 & 9.6 \\
$S D$ & 18.2 & 16.5 & & 46.9 & 17.8 \\
$\begin{array}{c}\text { Multiple } \\
M\end{array}$ & 2.0 & 3.5 & & 0.0 & 5.0 \\
$S D$ & 8.9 & 8.2 & & 0.0 & 15.4 \\
\hline
\end{tabular}

$33 \%$ vs. $M=9 \%, S D=22 \%)$, but not young adults $(t<1 ; M=$ $26 \%, S D=31 \%$ vs. $M=23 \%, S D=35 \%)$. This result contradicts the Age $\times$ Error Locus interaction predicted under editor theory: more error corrections on critical than noncritical segments, especially for young adults.

\section{Subsidiary Results}

Our subsidiary results either supported theoretical assumptions, provided manipulation checks, or seemed noteworthy as a stimulus to further research and theoretical development.

\section{Misperceptions}

A greater percentage of total trials involved misperceptions for older adults $(M=11.0 \%, S D=6.6 \%)$ than young adults $(M=$ $4.9 \%, S D=3.2 \%), t(62)=4.70, p<.01$. This age difference may reflect unsuspected age-linked declines in visual acuity. Unlike young adults, older adults claiming corrected-to-normal vision (as in the current study) often exhibit large close-range deficits when their acuity is tested (see MacKay, Taylor, \& Marian, 2002).

\section{Nonsequential Substitutions: Skill and Sympathy Effects}

Age and skill. Nonsequential substitution errors involving critical segments (/p/ or /b/, e.g., sop misproduced as "sod") were rare and did not differ by age $(t<1)$, which suggests that young and older adults were equally skilled at performing the required b-to-p or p-to-b transformation once they had identified what critical segment required transformation.

The sympathy effect. As in MacKay (1978), nonsequential substitutions involving noncritical consonants (e.g., peg misproduced as "peck") exhibited a directional bias involving the distinctive-feature /voicing/: For young and older adults combined, when the correct and substituted consonants differed in voicing (e.g., /peg/ and /peck/), the /+voice/ to /-voice/ change was more common than vice versa ( $75 \%$ vs. $25 \%$ ), and most voicing changes (75\%) mimicked the voicing change in the critical consonant:

\footnotetext{
5 This analysis required absolute counts per cell because there were so few multiple corrections.
} 
/+voice/ to /-voice/ for b-to-p transforms (e.g., peg misproduced as "peck") and /-voice/ to /+voice/ for p-to-b transforms (e.g., tabs misproduced as "labs"). These "sympathy effects," in which noncritical consonants "copied" the voicing change that occurred in critical consonants, support the conclusion of MacKay (1978) that the distinctive-feature voicing represents an independently controllable dimension in the hierarchy of units for producing syllables.

\section{Word-Frequency Effects}

To assess lexical-level involvement, we examined effects of stimulus frequency in by-items analyses, ${ }^{6}$ using Francis and Kucera (1982) to categorize our stimuli as high frequency (HF; $n=70$; range $=3-93 /$ million) versus low frequency (LF; $n=86$; range $=0-2 /$ million). A 2 (age) $\times 2$ (frequency) ANOVA on mean correct response times for HF versus LF stimuli yielded the usual effects of age, $F(1,154)=365.25, M S E=40,471, p<.01$, and frequency, $F(1,154)=13.52, M S E=59,107, p<.01$, with longer response times for LF than HF stimuli, but no Age $\times$ Frequency interaction $(p>.24)$. A similar ANOVA on the percentage of participants committing errors on HF versus LF stimuli yielded identical results. These effects of word frequency indicate that the present task involves word-level factors, and not just phonological factors, as might occur if participants transformed /p/ to /b/ or vice versa at a strictly phonemic level. These effects also comport with NST, in which word frequency reduces response times and errors because both depend on the strength of connections between every node in the production hierarchy, from lexical nodes to segment and phonological feature nodes.

\section{“Neither" Responses}

"Neither" responses (in which "neither" was the correct response) were more common as a percentage of valid control trials for young $(M=90.9 \%, S D=9.3 \%)$ than older adults $(M=$ $78.5 \%, S D=20.7 \%), t(62)=3.07, p<.01$. This difference was not due to response bias since a similar analysis of misses on experimental trials (i.e., nonidentification errors involving the response "neither" to stimuli containing /p/ or /b/) yielded no age effect $(t<1$; see Table 1). Nor was this finding due to a speedaccuracy trade-off because response times were longer for errors than correct responses on control trials (as described earlier for experimental trials).

\section{Discussion}

We first summarize our main age-linked results, separately for relative versus absolute frequency analyses. In relative frequency, omissions were more common for older than young adults, but older adults produced fewer nonsequential substitutions, marginally fewer nontransformation errors, and marginally fewer additions and sequential substitutions (combined) than young adults, and there were no age differences for fluency and nonidentification errors. In absolute frequency, older adults produced more suffix errors than young adults, more errors in words containing critical inflections, more errors on noninitial critical consonants, more misperceptions, more errors on control or "neither" trials, and more errors that resulted in real words. However, the absolute frequency of error corrections on control trials was greater for young adults than older adults, and there was no age difference in absolute frequency of errors involving noncritical inflections and syllable-initial critical consonants and errors resulting in nonwords. Finally, response times were longer for older than young adults, especially for responses that required phonological accommodation.

Considering age-independent effects, absolute frequency was greater for errors involving suffixes than other consonants in word-final position in the stimuli, and greater for word than nonword errors, which occurred less frequently than would be expected by chance. Effects of word frequency on response times and absolute error frequency indicated that our error-induction task involved word-level factors. Other response time results indicated that errors were not due to a speed-accuracy trade-off, and responses that did versus did not require phonological accommodation incurred a time cost for both young and older adults. However, response times for word versus nonword errors did not differ for either young or older adults.

The present results suggest three general conclusions. First, aging impairs two types of sequencing processes involving phonological and morphological units: context-based sequencing, whereby speakers select among variants of a suffix based on the nature of the prior (syllable-final) segment, and Lashley sequencing, whereby speakers produce preplanned speech sequences in proper order (when they do) and improper order (when they make sequencing errors). Similar age-linked Lashley-sequencing deficits have been observed in episodic memory tasks requiring immediate serial recall (e.g., Maylor et al., 1999). However, the Lashley sequencing underlying anticipatory and perseveratory substitutions of critical segments in the present task did not fit the "good" versus "bad" pattern predicted in Dell et al. (1997): an age-linked increase in perseveratory ("bad") errors and an age-linked decrease in anticipatory ("good") errors (but see Footnote 4). We observed neither an age-linked increase nor an age-linked decrease in experimentally induced perseverations and anticipations of older adults, which occurred with the same relative frequency as naturally occurring perseverations and anticipations in everyday speech. This correspondence suggests that the within-syllable perseverations and anticipations in the present paradigm may not differ fundamentally from the everyday perseverations and anticipations that occur between syllables and words.

A second general conclusion is that aging selectively increases the probability of some types of speech errors but not others. These results comport with the selective effects of aging on short-term episodic recall of letter sequences: As in the current study, omission errors were disproportionately more common for older adults in Maylor et al. (1999). However, differences between errors in episodic recall versus the production of familiar words should be noted. For example, unlike speech errors in the present study, all types of episodic errors were more common for older than young adults in Maylor et al. (1999).

Selective effects of aging are difficult to explain in theories that postulate a single age-linked factor with across-the-board effects (e.g., general slowing [Myerson et al., 1990] or inhibition deficits [Hasher \& Zacks, 1988]) but might be explainable in a multifactor

\footnotetext{
${ }^{6}$ There were too few errors on HF words for a by-participants analysis
} 
theory that includes as factors general slowing and frontal decline (including inhibition deficits; see Maylor et al., 1999). However, the present speech error results challenge the multifactor theory of Salthouse (1996), in which one factor (general slowing) degrades cognitive performance through its effects on another factor (forgetting or unavailability of the products of earlier processing at the time when later processing requires those products). It is unclear what interdependent earlier and later processing products this theory might postulate for producing short words, in which coarticulation often spans the entire output. Nor is it clear how these products could become unavailable or forgotten in the brief time it took older adults to produce the short words in the present study. Nor is it clear how age-linked slowing and forgetting could increase the proportion of some error types but reduce the proportion of others (e.g., nonsequential substitutions).

Our third general conclusion is that interactive-activation theories (e.g., Dell, 1986; Harley, 1984; MacKay, 1987) are better suited for explaining the present speech error results than serialstage theories (e.g., Fromkin, 1970; Levelt et al., 1991). Effects of lexical frequency indicated that our error induction task involves lexical-level processing, satisfying the precondition for testing both interactive activation and serial-stage theories. However, the lexical bias effect in the present results indicates a retroactive effect of phonology on lexical retrieval that supports interactiveactivation theories such as NST, but not the independent sequentially ordered stages for phonological and word-level retrieval in stage theories. Under NST, the most-primed-wins activation principle explains how word status shapes phonological errors: Because lexical nodes have bidirectional connections to phonology (bottom-up for perception and top-down for production), bottom-up phonological priming can retroactively determine what lexical node receives most priming and becomes activated in error. However, this retroactive effect is not possible for nonword outcomes (which lack lexical nodes).

Like the Salthouse (1996) theory, NST and the transmission deficit hypothesis constitute a multifactor theory because effects of one factor (age-linked transmission deficits) depend on other factors (e.g., the structure of preformed connections for executing a behavior). However, NST provides a promising account for many aspects of the present data. Under NST, age-linked transmission deficits caused the age-linked decrease in nonsequential substitutions (reflecting excessive priming in young adults) and the agelinked increase in omissions (reflecting insufficient priming in older adults). Similarly, an age-linked increase in errors occurred in syllable-final but not syllable-initial position under NST because priming must traverse more connections to enable activation of syllable-final segments. This increases the probability of syllable-final omissions because effects of age-linked transmission deficits increase with each additional connection that priming must traverse (see MacKay \& Burke, 1990).

Under NST, we observed an age-linked increase in word errors because the preformed connections for producing familiar words are very strong in older adults, who have produced these words for many more years than young adults. However, we observed no age-linked increase in nonword errors because representing and producing nonwords as coherent units requires new connection formation, a process subject to age-linked decline (see, e.g., MacKay \& James, 2001). We likewise observed a greater agelinked increase in errors on suffixes versus other syllable-final consonants because new connection formation is required to represent and produce suffixes but not syllable-final segments in familiar words (see, e.g., MacKay \& James, 2001). Age-linked deficits in connection formation (see, e.g., MacKay \& Abrams, 1996), therefore, made suffixes more error prone than syllablefinal consonants for older adults.

Finally, we observed an age-linked decline in error corrections on control trials because error detection and correction involves new connection formation under NST, a process subject to agelinked decline (see e.g., MacKay \& Abrams, 1996). Editor theories (e.g., Levelt, 1989) can likewise explain this age-linked decline in error correction if internal editing becomes less efficient with aging. However, other studies have failed to observe age-linked declines in lexical error correction (McNamara, Obler, Au, Durso, \& Albert, 1992), orthographic error correction (MacKay et al., 1999), orthographic error detection (MacKay et al., 1999; Shafto, 2002), and keypress error detection (Rabbitt, 1979), and the present data fit this pattern of mixed support: For experimental trials in the present study, young adults detected and corrected their errors no more often than older adults, and, contrary to post hoc predictions derived from editor theories, there was no agelinked increase in the probability of correcting errors on critical than noncritical segments, and no age-linked increase in the relative frequency of three-time versus two-time corrections in multiple error corrections.

\section{NST and Relations Between Aging and Sequencing}

Three findings in the current study suggest a special relation between aging and sequencing processes: the age-linked increase in errors on stimuli with critical but not noncritical inflections, the age-linked increase in response times for stimuli with critical versus noncritical inflections, and the age-linked increase in sequential but not nonsequential substitution errors. To stimulate further research on age-linked sequencing effects, we next develop a tentative account of aging and sequencing processes within the NST framework.

\section{Aging and the Sequencing of Phonological Segments}

Under NST, the special activating device known as sequence nodes may be central to the present age-linked increase in sequential substitution errors. Sequence nodes are stored separately from the content nodes illustrated in Figure 1, and inhibitory connections between sequence nodes represent sequence rules that determine the activation order of content nodes (see, e.g., Santiago, MacKay, Palma, \& Rho, 2000). For example, to produce the word plush, inhibitory connections between the sequence nodes representing the domains "initial stop" and "initial liquid" control activation-order for the simultaneously primed phonological content nodes representing /p/ and /l/ (see Figure 1). Age-linked impairment of inhibitory interactions between sequence nodes may, therefore, exacerbate sequential errors under NST.

The idea that cognitive aging impairs inhibitory processes is, of course, not new: Its history extends from Pavlov (see WoodruffPak, 1997, p. 164) to Hasher and Zacks (1988). However, our hypothesis differs from the Hasher-Zacks hypothesis in three respects. First, unlike the Hasher-Zacks hypothesis, in which all age-linked cognitive declines reflect inhibition deficits, we limit 
our hypothesis to the inhibition between phonological sequence nodes because inhibition comes in many different forms and contexts in normal brain functioning (see, e.g., Woodruff-Pak, 1997, pp. 164-171). Second, our hypothesis applies to phonology, whereas Zacks and Hasher (1997) exempt phonology and other automatic processes from age-linked inhibition deficits. Third, we define inhibition theoretically, whereas Hasher and Zacks define inhibition in terms of task-specific empirical effects (e.g., interference in negative priming and Stroop tasks), a problematic definition because processes other than inhibition can cause interference (see, e.g., MacKay, Miller, \& Schuster, 1994).

\section{Aging, Phonological Accommodation, and Context-Based Sequencing}

Under NST, different factors may underlie age-linked deficits involving Lashley sequencing versus context-based sequencing. To appreciate this point requires a detailed analysis of phonological accommodation processes in NST. Consider production of the plural noun cups illustrated in Figure 6. When cups(plural noun) is activated as the most primed node in its domain, the noun cup and the node representing the concept PLURAL are primed and activated in sequence. After activation of cup, its phonological constituents are primed top-down and then activated in sequence. After activation of PLURAL, its connected node in the phonological system, PLURAL ARCHPHONEME, becomes primed topdown and activated. Activation of PLURAL ARCHPHONEME, in turn, simultaneously primes its connected nodes: the alternative suffixes for forming regular English plurals, including /-s/ and /-z/ (see Figure 6). Both suffixes will receive equivalent top-down priming, but one will accumulate additional priming depending on whether the immediately prior syllable-final segment is unvoiced (e.g., /p/) or voiced (e.g., /b/). The reason is that connections within the phonological system are bidirectional: The same phonological

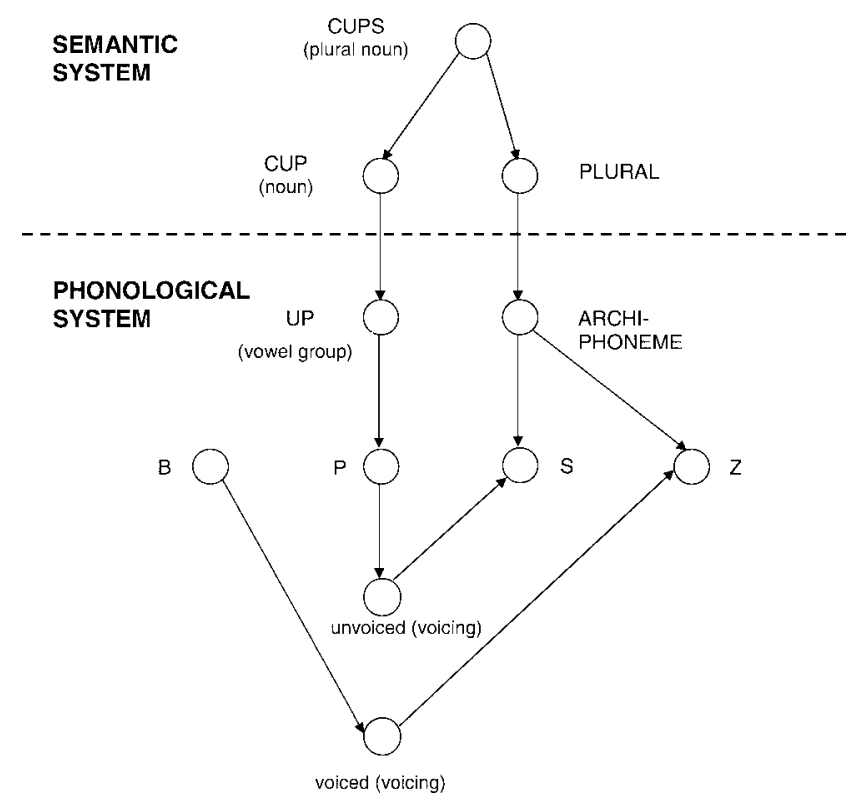

Figure 6. A subset of the nodes and connections involved in producing the nouns cups and cubs in node structure theory (see text for explanation). node requires bottom-up connections for perception and top-down connections for production. This means that when producing the noun cups, bottom-up connections from syllable-final /p/ prime the plural suffix /-s/ via the feature /-voice/, and bottom-up connections from syllable-final $/ \mathrm{b} /$ prime the plural suffix /-z/ via the feature /+voice/ (see Figure 6). Summated top-down and bottom-up priming will therefore be greater for plural suffix /-s/ than /-z/ after unvoiced segments but vice versa after voiced segments. The most-primed-wins activation principle will therefore ensure automatic activation of the context-appropriate suffix (e.g., /-s/ after syllable-final /p/, and /-z/ after syllable-final /b/), as observed in the present error-induction task.

Consider now the "distance" that priming must traverse to enable activation of the most primed node in the domains for regular plural suffixes versus other syllable-final segments. As Figure 6 illustrates, priming traverses fewer connections to reach syllable-final segments (that only require top-down priming) than plural suffixes (that also require bottom-up priming and new connection formation). This means that aging is more likely to impair production of suffixes than syllable-final segments because the magnitude of age-linked transmission deficits will increase with each additional connection that priming must traverse (see MacKay \& Burke, 1990). As a result, older adults will be especially likely to omit suffixes relative to syllable-final segments, an alternate explanation for the observed age-linked increase in errors involving suffixes versus other syllable-final consonants.

The architecture of connections involved in the present transform task may also explain why response times are especially long and errors especially likely when older adults transform stimuli with critical inflections and why the errors involve both the inflections themselves and other segments in stimuli with critical inflections. By way of illustration, when the $/ \mathrm{p} /$ is changed to $/ \mathrm{b} /$ in words ending in a critical suffix (e.g., CUPS), the lexical nodes $c u b$ (noun) and cubs(plural noun) must be activated via bottom-up priming to ensure that adding a plural suffix will generate an actual English word. Then the hierarchy of nodes for producing cubs(plural noun) becomes primed and activated in sequence, including the /-z/ suffix. However, /-z/ will receive strong competition from /-s/ for most primed status in the domain of plural suffixes because of the priming /-s/ receives during perception of the original stimulus, CUPS. Moreover, stimuli with critical inflections will also trigger similar competition within the domain of vowel group units, which differ for the stimulus versus the response. For example, the vowel group is $u p$ (vowel group) for the stimulus CUPS, but $u b$ (vowel group) for the intended response cubs. By contrast, no corresponding competition exists when transforming stimuli with noncritical inflections (e.g., PUCKS and BANS) because the suffix and vowel group remain unchanged from stimulus to response.

Because competition for most primed status in a domain is the basic cause of speech errors, this may explain why the error increase for words with critical versus noncritical inflections involved both the critical inflections themselves and other segments in words with critical inflections. This competition factor may also explain the especially long response times for inflections that required phonological accommodation after a new syllable-final segment was "imported" in the present task. Moreover, aging increased these competition effects because priming must traverse more connections in producing stimuli with critical than noncritical inflections, and with each additional connection that priming 
traverses, age-linked transmission deficits increase the summation time required to win the competition or achieve most-primed status in any given domain (see MacKay \& Burke, 1990).

\section{References}

Allen, P. A., Madden, D. J., Weber, T. A., \& Crozier, L. C. (1992). Age differences in short term memory: Organization or internal noise? Journal of Gerontology: Psychological Sciences, 47, 281-288.

Au, R., Joung, P., Nicholas, M., Obler, L. K., Kass, R., \& Albert, M. L. (1995). Naming ability across the lifespan. Aging \& Cognition, 2, 300-311.

Baars, B. J., Motley, M. Y., \& MacKay, D. G. (1975). Output editing for lexical status in artificially elicited slips of the tongue. Journal of Verbal Learning and Verbal Behavior, 14, 382-391.

Burgess, N. (1995). A solvable connectionist model of immediate recall of ordered lists. In G. Tesauro, D. S. Touretzky, \& T. K. Leen (Eds.) Advances in neural information processing systems. Cambridge, MA: MIT Press.

Burke, D. M., MacKay, D. G., \& James, L. E. (2000). Theoretical approaches to language and aging. In T. J. Perfect \& E. A. Maylor (Eds.), Models of cognitive aging (pp. 204-237). Oxford, England: Oxford University Press.

Burke, D. M., MacKay, D. G., Worthley, J. S., \& Wade, E. (1991). On the tip of the tongue: What causes word finding failures in young and older adults? Journal of Memory and Language, 30, 542-579.

Dell, G. S. (1986). A spreading-activation theory of retrieval in sentence production. Psychological Review, 93, 283-321.

Dell, G. S. (1990). Effects of frequency and vocabulary type on phonological speech errors. Language and Cognitive Processes, 5, 313-349.

Dell, G. S., Burger, L. K., \& Svec, W. R. (1997). Language production and serial order: A functional analysis and a model. Psychological Review, 104, 123-147.

Dell, G. S., \& Reich, P. A. (1981). Toward a unified model of slips of the tongue. In V. A. Fromkin (Ed.), Errors in linguistic performance (pp. 273-286). New York: Academic Press.

Francis, W. N., \& Kucera, H. (1982). Frequency analysis of English usage: Lexicon and grammar. Boston: Houghton Mifflin.

Fromkin, V. A. (1970). The non-anomalous nature of anomalous utterances. Language, 46, 27-52.

Fromkin, V. A. (1973). Speech errors as linguistic evidence. The Hague: Mouton.

Garnham, A., Shillcock, R. C., Brown, G. D. A., Mill, A. I. D., \& Cutler, A. (1982). Slips of the tongue in the London-Lund corpus of spontaneous conversation. In A. Cutler (Ed.), Slips of the tongue and language production (pp. 251-263). New York: Mouton.

Harley, T. A. (1984). A critique of top-down independent levels models of speech production: Evidence from non-plan-internal speech errors. Cognitive Science, 8, 191-219.

Hasher, L., \& Zacks, R. T. (1988). Working memory, comprehension, and aging: A review and a new view. In G. H. Bower (Ed.), The psychology of learning and motivation (Vol. 22, pp. 193-225). San Diego, CA: Academic Press.

Keele, S. W. (1987). Sequencing and timing in skilled perception and action: An overview. In A. Allport, D. G. MacKay, W. Prinz, \& E. Scheerer (Eds.), Language perception and production: Relationships between listening, speaking, reading and writing (pp. 463-487). London: Academic Press.

Kemper, S. (1992). Adults' sentence fragments: Who, what, when, where, and why. Communication Research, 19, 444-458.

Lashley, K. S. (1951). The problem of serial order in behavior. In L. P. Jeffress (Ed.), Cerebral mechanisms in behavior: The Hixon symposium (pp. 112-146). New York: Wiley.

Levelt, W. J. M. (1989). Speaking: From intention to articulation. Cambridge, MA: MIT Press.
Levelt, W. J. M., Schreifers, H., Vorberg, D., Meyer, A. S., Pechman, T. \& Havinga, J. (1991). The time course of lexical access in speech: A study of naming. Psychological Review, 98, 122-142.

MacKay, D. G. (1970). Spoonerisms of children. Neuropsychologia, 8, 315-322.

MacKay, D. G. (1971). Stress pre-entry in motor systems. American Journal of Psychology, 84, 35-51.

MacKay, D. G. (1972). The structure of words and syllables: Evidence from errors in speech. Cognitive Psychology, 3, 210-227.

MacKay, D. G. (1976). On the retrieval and lexical structure of verbs. Journal of Verbal Learning \& Verbal Behavior, 15, 169-182.

MacKay, D. G. (1978). Speech errors inside the syllable. In A. Bell \& J. B. Hooper (Eds.), Syllables and segments (pp. 201-212). Amsterdam: North-Holland.

MacKay, D. G. (1979). Lexical insertion, inflection and derivation: Creative process in word production. Journal of Psycholinguistic Research, 8, 477-498.

MacKay, D. G. (1987). The organization of perception and action: A theory for language and other cognitive skills. New York: SpringerVerlag.

MacKay, D. G. (1990). Perception, action, and awareness: A three-body problem. In O. Neumann \& W. Prinz (Eds.), Relationships between perception and action (pp. 269-303). Berlin: Springer-Verlag.

MacKay, D. G. (1992). Awareness and error detection: New theories and paradigms. Consciousness and Cognition, 1, 199-225.

MacKay, D. G., \& Abrams, L. (1996). Language, memory, and aging: Distributed deficits and the structure of new-versus-old connections. In J. E. Birren \& W. K. Schaie (Eds.), Handbook of the Psychology of Aging (4th ed., pp. 251-265). San Diego: Academic Press.

MacKay, D. G., Abrams, L., \& Pedroza, M. J. (1999). Aging on the input versus output side: Theoretical implications of age-linked asymmetries between detecting versus retrieving orthographic information. Psychology and Aging, 14, 3-17.

MacKay, D. G., \& Burke, D. M. (1990). Cognition and aging: A theory of new learning and the use of old connections. In T. M. Hess (Ed.), Aging and cognition: Knowledge organization and utilization (pp. 213-263). Amsterdam: North-Holland.

MacKay, D. G., \& James, L. E. (2001). The binding problem for syntax, semantics, and prosody: H. M.'s selective sentence reading deficits under the theoretical-syndrome approach. Language and Cognitive Processes, 16, 419-460

MacKay, D. G., Miller, M. D., \& Schuster, S. P. (1994). Repetition blindness and aging: Evidence for a binding deficit involving a single theoretically specified connection. Psychology and Aging, 9, 251-258.

MacKay, D. G., Taylor, J. K., \& Marian, D. E. (2002, April). Unsuspected age-linked deterioration of vision: Practical implications for older adults, empirical implications for studies of reading. Poster presented at the Cognitive Aging Conference, Atlanta, GA.

Mahoney, P. G. (1997). Language production, speech errors, and aging (Doctoral dissertation, The Claremont Graduate School, 1997). Dissertation Abstracts International, 58, 2148.

Maylor, E. A., Vousden, J. I., \& Brown, G. D. A. (1999). Adult age differences in short-term memory for serial order: Data and a model. Psychology and Aging, 14, 572-594.

McCrae, R. R., Arenberg, D., \& Costa, P. T. (1987). Declines in divergent thinking with age: Cross-sectional, longitudinal, and cross-sequential analyses. Psychology and Aging, 2, 130-137.

McNamara, P., Obler, L. K., Au, R., Durso, R., \& Albert, M. (1992). Speech monitoring in Alzheimer's disease, Parkinson's disease, and normal aging. Brain and Language, 42, 38-51.

Meringer, R., \& Mayer, K. (1895). Versprechen und verlesen: Eine psychologische-linguistische studie. Stuttgart, Germany: Goeschense Verlagsbuchhandlung.

Myerson, J., Hale, S., Wagstaff, D., Poon, L. W., \& Smith, G. A. (1990). 
The information-loss model: A mathematical theory of age-related cognitive slowing. Psychological Review, 97, 475-487.

Rabbitt, P. (1979). How old and young subjects monitor and control responses for accuracy and speed. British Journal of Psychology, 70, 305-311.

Rabbitt, P. (1990). Age, IQ and awareness, and recall of errors. Ergonomics, 33, 1291-1305.

Rapp, B., \& Goldrick, M. (2000). Discreteness and interactivity in spoken word production. Psychological Review, 107, 460-499.

Salthouse, T. A. (1996). The processing-speed theory of adult age differences in cognition. Psychological Review, 103, 403-428.

Santiago, J., MacKay, D. G., Palma, A., \& Rho, C. (2000). Picture naming latencies vary with sequential activation processes in hierarchic syllable and word structures. Language and Cognitive Processes, 15, 1-44.

Schmitter-Edgecombe, M., Vesneski, M., \& Jones, D. W. R. (2000). Aging and word finding: A comparison of spontaneous and constrained naming tests. Archives of Clinical Neuropsychology, 15, 479-493.
Shafto, M. A. (2002). Orthographic error monitoring in older adults (Doctoral dissertation, University of California, Los Angeles, 2002). Dissertation Abstracts International, 63, 1584.

Valencia-Laver, D. (1992). Adult age differences in the production, detection, and repair of speech errors (Doctoral dissertation, The Claremont Graduate School, 1992). Dissertation Abstracts International, 53, 1626.

Woodruff-Pak, D. S. (1997). The neuropsychology of aging. Malden, MA: Blackwell.

Zacks, R. T., \& Hasher, L. (1997). Cognitive gerontology and attentional inhibition: A reply to Burke and McDowd. Journal of Gerontology: Psychological Sciences, 52, 274-283.

Received July 30, 2002

Revision received May 9, 2003

Accepted May 30, 2003

\section{ORDERFORM}

Start my 2004 subscription to Psychology and Aging!

ISSN: 0882-7974

\section{\$59.00, APA Member/AfFiliate $\$ 119.00$, INDIVIDUAL NonMember $\$ 298.00$, Institution In DC add $5.75 \%$ / In MD add 5\% sales tax Total Amount Enclosed \\ $\$$}

Subscription orders must be prepaid. (Subscriptions are on a calendar year basis only.) Allow 4-6 weeks for delivery of the first issue. Call for international subscription rates.

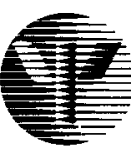

SEND THIS ORDER FORM TO:

American Psychological Association

Subscriptions

750 First Street, NE

Washington, DC 20002-4242

AMERICAN

PSYCHOLOGICAL

ASSOCIATION
Or call (800) 374-2721, fax (202) 336-5568.

TDD/TTY (202) 336-6123.

For subscription information, e-mail: subscriptions@apa.org
Send me a FREE Sample Issue

Check enclosed (make payable to APA)

Charge my: $\bigcirc$ viSA $\bigcirc$ MasterCard $\bigcirc$ American Express

Cardholder Name
Card No. $\_$Exp. Date
BILLING ADDREature (Required for Charge)

\begin{tabular}{l}
\hline City $\_$State _ Zip \\
Daytime Phone ___ \\
E-mail \\
SHIP TO: \\
Name \\
Address \\
\hline City \\
APA Member \#
\end{tabular}

